\title{
Article
}

\section{Happy Environments: Bhutan, Interdependence and the West}

\section{Randy Schroeder ${ }^{1, *}$ and Kent Schroeder ${ }^{2}$}

1 Departments of General Education and English, Mount Royal University, 4825 Mount Royal Gate SW, Calgary, AB T3E 6K6, Canada

2 International Development Institute, Humber College, 3199 Lake Shore Blvd. West, Toronto, ON M8V 1K8, Canada; E-Mail: kent.schroeder@humber.ca

* Author to whom correspondence should be addressed; E-Mail: rschroeder@mtroyal.ca; Tel.: +1-403-440-6265; Fax: +1-403-440-6526.

Received: 28 March 2014; in revised form: 21 May 2014 / Accepted: 23 May 2014 /

Published: 30 May 2014

\begin{abstract}
There is a growing trend to understand economic and environmental policies in terms of multiple dimensions and "interdependence." Bhutan is increasingly seen as an operational model with its Gross National Happiness (GNH) strategy. GNH, which is rooted in Mahayana Buddhism, is a framework and set of policy tools that conceptualizes sustainability as interdependent ecological, economic, social, cultural and good governance concerns. Bhutan's practical GNH experience illustrates a significant ability to positively couple economic growth with a healthy environment. Can the "West" - with its legacy of either/or economics-learn anything from Bhutan's multidimensional policy experiment? At first, it would seem not. It is questionable whether the West can replicate Bhutan's unorthodox policy tools as we do not have a balancing set of Buddhist values rooted in mainstream culture. We are not equipped to respond to the many unintended consequences of interdependent policy because we do not yet understand what "interdependence" actually entails. There is hope, but much of it exists in the grey literature of ecological economics. This literature is in urgent need of greater exposure if we are to imagine and enact sustainability policy tools that are truly sensitive to interdependence, and thus follow Bhutan on its perilous but necessary journey.
\end{abstract}

Keywords: Bhutan; Buddhism; environmental and economic interdependence; Gross National Happiness; sustainability policy 


\section{Introduction}

Policy that promotes economic growth has regularly taken centre stage since the economic crisis of 2008. Yet this masks another recent global trend towards positively integrating economic growth with environmental and other concerns. The Organisation for Economic Co-operation and Development's (OECD's) Measuring the Progress of Societies project, the Stiglitz report, the Canadian Index of Well Being, the UK's multidimensional well-being measures, all exemplify a global trend to understand economic, environmental and other policies in terms of multiple dimensions and "interdependence". The Himalayan country of Bhutan is increasingly seen as an operational model of policy interdependence, given its constitutional directive and governance tools: All prioritize a balanced approach that integrates ecology, economy, social equity, culture and good governance. It is a model that attempts to decouple the economy from negative environmental externalities, recognizing the further interdependence of both with social, cultural and governance policies and concerns. However, it is becoming clear that Bhutan's interdependent sustainability policy framework and its attempt to move beyond traditional economic growth models, is still evolving. Can the "West"-with its legacy of either/or economics and ecology, its residual understanding of "rational actors" in the marketplace, its valuation of utility and objectively measurable "data"-learn anything from Bhutan's multidimensional experiment? At first, the answer would seem "no." It is questionable whether our "mature" democracies could implement Bhutan's unorthodox policy approach to sustainability, because we do not have a balancing set of Himalayan Buddhist values (or some analog) rooted in mainstream culture. We have a long history of ontological miscalculation. We are not equipped philosophically or practically to respond to the relentlessly evolving nature of interdependent environmental and economic policy, because we do not yet understand what "interdependence" actually entails. At the same time, the Bhutanese experience offers clues to how the West might better respond to positively coupling economic growth policies with a healthy environment. This paper explores these issues through three sections. Section 1 examines the nature of Bhutan's interdependent policy framework and its distinctly Buddhist character. Section 2 explores differences in understanding the nature of interdependency in Buddhist and western philosophical traditions, and the resulting implications for sustainability policy. Given these differences and their implications for whether the West can draw on Bhutan's experience, Section 3 concludes the paper with a number of recommendations - both abstract and concrete - for how the West might engage in the policy process in a way that better integrates interdependent economic and environmental concerns.

\section{Interdependent Policy in Bhutan}

Bhutan is the only country in the world that is formally committed to the pursuit of happiness as a central policy goal [1]. Gross National Happiness (GNH) is the guiding development strategy, a unique operational vision that rejects pure economic growth for its own sake in favor of balance, holism and integrated multidimensionality. Gross National Happiness starts from the assumption that happiness is a universal aspiration that has multiple dimensions beyond income. Happiness, not a singular focus on economic growth, should therefore be the end goal of development if development is to be sustainable. As a strategy, GNH policy pursues the creation of the enabling conditions for individual and collective 
happiness [2-6]. According to Karma Tshiteem, Secretary of the Gross National Happiness Commission, the apex body responsible for operationalizing GNH in Bhutan: "Happiness still remains an individual responsibility, but the State makes sure that the necessary conditions are there for people to pursue the path they choose" [7] (p. 34).

GNH was initially conceived as four interrelated pillars-equitable socio-economic development, environmental sustainability, cultural preservation and promotion, and good governance-but has more recently been expanded into nine integrated domains made up of 33 indicators further disaggregated into over 100 variables [8]. These multiple dimensions of GNH are understood as interdependent, involving reciprocal connections among the dimensions that are ongoing, evolutionary and unpredictably emergent. According to McDonald, the GNH dimensions must be understood as “... overlapping domains of interaction, ones which are truly inseparable from each other" [9] (p. 32). Policy formulation and implementation therefore requires a "meticulous orchestration" of the dimensions of GNH as a means to promote the conditions for happiness [10] (p. 30). A singular focus on economic policy or environmental policy_familiar to us in the West - is replaced by an understanding of policy domains that interact deeply with one another in an ongoing way. Since 2008, Bhutan has developed a range of policy tools that direct policy actors to design, implement and measure all policies in a way that incorporates GNH's interdependent approach to sustainability [8,11]. The policy tools intend to ensure interdependent balance across the dimensions of GNH, where economic concerns do not overwhelm other policy concerns. Environmental conservation policy is therefore not an impediment to economic growth; it is tightly and inherently integrated with it.

This approach to happiness rooted in interdependent environmental, economic, social, cultural and governance conditions is distinctly grounded in Mahayana Buddhism [12-16]. Key is the disarticulation of "happiness" from individual pleasure, joy and satisfaction, in favor of a subtle understanding of multiple evolving synergies, where radical acceptance of the world is paired with radical intervention in the world. The happiness that GNH strives to foster is a state of consciousness known as "sukha". Unlike notions of happiness as immediate pleasure fulfillment, sukha balances mental, emotional and spiritual conditions regardless of changes in material conditions [17] (pp. 59-60), [18] (pp. 274-275). It is deeper, more stable understanding of happiness as "a state of flourishing that arises from mental balance and insight into the nature of reality" [17] (p. 60). Material conditions may be important to avoid dissatisfaction but are not the core of happiness. Interdependence, balance and harmony are values that are the foundation of happiness.

Already this notion of happiness presents as a paradox for the West, where GNH is sometimes dismissed as vague, utopian and quaint. The immediate question is whether the operationalization of $\mathrm{GNH}$, and the notion of happiness it implies, is a reflection of the set of GNH policy institutions and instruments, or the fruit of longstanding cultural heritage, or both. Whatever the case, Bhutan can point to some striking accomplishments since the inauguration of GNH in the early 1970s, particularly given that life in Bhutan in the 1960s looked little different than it did in the 1500s [19] (p. 211). These accomplishments demonstrate a meaningful approach to sustainability where environmental conditions have thrived alongside economic growth. Annual economic growth in the country has been dramatic, reaching 8.7\% between 2005 and 2010, placing it second to China in the region [20] (p. 31). This growth has occurred alongside an internationally recognized record on environmental conservation. Article 5.3 of the Bhutanese constitution requires $60 \%$ of the country be covered in forest for all time. The actual figure is currently just over $70 \%$ and increases to $81 \%$ if shrubs are included [21] (p. 76), [22] (p. 8). Bhutan is also 
recognized as part of one of the world's "bio-diversity hotspots" [23]. It has over 7000 species of vascular plants, 200 species of mammals and 770 species of birds [22] (pp. 8-9). Bio-diversity has been promoted through the creation of protected areas that are linked by biological corridors. Currently, these protected areas and biological corridors make up 51\% of Bhutan's total area, higher than any other country in the world [23] (pp. 12-13), [24] (pp. 29-30). In addition to its rich bio-diversity, Bhutan committed itself to remaining carbon neutral in perpetuity at the 15 th Conference of Parties to the United Nations Framework Convention on Climate Change (UNFCCC) in Copenhagen in 2009.

Bhutan's impressive economic and environmental achievements are notable on their own terms. The interdependencies within GNH, however, further integrate economic and environmental concerns to social, cultural and governance issues. For example, education is free and the country's mean years of schooling has moved from the lowest in the region to the highest, equivalent to China's [20] (p. 28). Free health care has contributed to life expectancy increasing from 38 years to 69 years over the last four decades while infant mortality rates have dropped from 102.8 per 1000 live births in 1994 to 47 in 2010 [20], (pp. 30,94). Paralleling these socio-economic advances has been a purposeful process of decentralization and democratization. The process resulted in a peaceful transition to a constitutional monarchy in 2008 and a peaceful transfer of power to the opposition in Bhutan's second democratic election in 2013. Bhutan is also ranked by Transparency International as the least corrupt country in South Asia [25].

Beyond these broader outcomes, narrowing focus to a specific policy field is instructive for understanding the operationalization of GNH in practice. Tourism policy in Bhutan provides an interesting case where fostering balance among the interdependent GNH dimensions replaces the focus of maximizing GDP. Bhutanese tourism policy uses an all-inclusive daily tourist tariff as a tool to balance the GNH dimensions. Independent travel is not allowed in the country, requiring international tourists to take an all-inclusive package tour for which they pay an expensive daily tariff in foreign currency. The intention of this policy is twofold. First, the high cost of the tariff minimizes the number of tourists able to afford visiting Bhutan as a way to limit potential ecological and cultural erosion that large numbers of tourists would bring. Second, the high cost also generates significant economic growth despite the limit it places on actual tourist numbers. The tariff is therefore a single tool that balances the socio-economic, environmental and cultural dimensions of GNH by fostering controlled economic growth that limits negative impacts on ecological and cultural ecological systems.

The role of the environmental and cultural dimensions of GNH in tourism policy is not limited, however, to their preservation. Paralleling the tariff are specific kinds of tourism packages offered by Bhutan. These focus on promoting, not just preserving, the country's pristine environment and traditional culture. The uniqueness of Bhutan's culture and environment is used as a tourism product meant to attract high paying tourists. Bhutan's environment and culture need to be protected from the potential excesses of unchecked economic growth through mass tourism while simultaneously acting as the drawing card to attract a limited number of high paying tourists. Protection and promotion go hand in hand. The result is a potentially virtuous GNH circle: Preserving the country's environment and culture will reduce negative externalities arising from tourism and keep both the environment and culture intact; actively promoting this protected environment and culture will, in turn, increase Bhutan's attraction as a unique tourist destination for those willing to pay a premium, further fueling economic growth and consolidating Bhutan's ecological and cultural identity. 
Bhutan's GNH approach to tourism is not without its challenges. Tourism governance, another dimension of GNH, currently partners multiple government ministries, the private sector and civil society organizations in the Tourism Council of Bhutan (TCB). TCB is responsible for tourism policy design and implementation. This multi-partner and multi-sectoral approach is the foundation of a policy process that recognizes the interdependence of GNH dimensions, yet it is not without its political conflicts over how these dimensions should be balanced in practice. Indeed, significant conflict and disagreement has occurred among state and non-stake tourism stakeholders as well as within the Bhutanese state itself over the proper balance of GNH dimensions [26], (pp. 146-186). Moreover, the tariff and required tour packages that are at the centre of Bhutanese tourism policy do not apply to tourists from India, Bangladesh and Maldives, adding a significant geopolitical wrinkle to GNH [27].

Despite the challenges, the tourism outcomes that have been generated by Bhutan's GNH approach are notable, particularly when compared to a neighbouring country like Nepal that promotes mass tourism. Bhutan's yearly international tourist arrivals are tiny in comparison to Nepal yet in both cases tourism is one of the largest contributors to their respective economies [28]. At the same time, Nepal's focus on maximizing tourist arrivals has contributed to significant cultural erosion, environmental degradation and social problems while Bhutan's integrated GNH approach has largely avoided these [28]. Bhutan's choice to pursue tourism policy that tightly integrates managed economic growth with environmental and cultural considerations has likely meant foregoing significantly greater economic benefits, but it has promoted a much more sustainable path. Overall, the overview above of both general GNH policy outcomes and tourism policy in particular demonstrates that the range of GNH outcomes in Bhutan is impressive from a sustainability perspective. At the same time, the outcomes of GNH should not be romanticized, for a number of reasons:

- A significant decrease in poverty measured as household consumption occurred from 2007 to 2013 but poverty remains a distinctly rural phenomenon in Bhutan [29].

- The structure of Bhutan's economy has increasingly moved away from agriculture, particularly in light of its growing hydropower industry. The shift in the nature of economic output, however, is not matched by changes in the employment structure, which continues to remain predominantly agricultural [30], (p. 11).

- Youth unemployment is on the rise, moving from 2.6\% in 1998 to $9.9 \%$ in 2007 [20], (p. 33), likely a reflection of increasing rural-urban migration.

- Gender disparities also exist, particularly in terms of political participation, employment, and representation in tertiary education [31].

- Bhutan has also not been able to resolve a refugee crisis that began in the early 1990s rooted in a conflict involving its minority ethnic-Nepalese population. Large numbers fled to refugee camps in Nepal. An inability of Bhutan and Nepal to develop a successful citizenship verification process has led to third country resettlement as the means to address the situation.

Bhutan's multidimensional policy achievements are nonetheless viewed by many commentators as uniquely impressive [1] (p. 3), [2], [15] (pp. 25-26). Its GNH strategy has promoted a sustainability framework that links happiness to the interdependencies among economic, environmental and social systems. What can we learn? A primary problem is that, as regards the Himalayan notion of happiness, 
we have few parallels in the West. The synergy derived from the interdependent and interacting dimensions of GNH is deeply tied to the strategy's Buddhist foundation. As Ross McDonald has argued, for those of us in the West it is "very easy to completely miss the deeper synergies implied by GNH thinking and to completely miss that fact that we miss this" [32] (p. 616).

\section{Interdependence and the West}

In Money, Sex, War, Karma, Buddhist scholar David Loy presents a familiar argument: Our Judeo-Christian heritage has given those of us in the West a false dichotomy between humans and nature, while our Greek heritage has given us a similar distinction between the social and the natural [33]. The result is a variety of worldviews that construct the "environment" as resource and technology as resource extractor. Loy goes further, to speculate collective analogs to individual suffering, expressed in the structures of our societies, all of which posit and value the atomized, reified individual: corporations institutionalize greed; military complexes institutionalize ill will; 24-hour news cycles institutionalize delusion. By "reified individual," Loy means the Cartesian Self, imagined as a stand-alone entity: coherent over time, self-directed, and conceptually distinct from the networks that create and sustain it. He means the individualized Self that, while interactive with nature and culture, is still understood as separate from both of them. He means the Self that is necessary to Western law and governance; he means the Self that Buddhism considers delusory, and the source of suffering.

At the core of Loy's argument is the assumption that interdependence — what we might consider the rejection of reified Selfhood - is both therapeutic and fairly easy to understand. Interdependence, on this view, would mean the dense networks of reciprocal, causal, ecosystemic relations within systems (indeed, within the universe considered as a kind of mega-system). But as Buddhist scholar Andrew Olendzki notes, "interdependence," in the West, tends to rest upon spatial metaphors [34] (p. 105). As such, it reprises the whole lineage of "substantialist" thinking that compromises an accurate understanding of interdependence, and calcifies the nominal forms of language that stress nouns and their qualities. Put another way, more substantialist notions of interdependence resist the parallel—but much less influential - strain of historical Western thought that is often labeled "process-relational" thinking, a strain that would be more appropriate and accurate to Bhutan's understanding of interdependence (more on process and relation below). In everything from our literature to our legal system, the individual Self is assumed to be a noun-a persistent, self-coherent, discrete substance - instead of a series of verbs or trajectory of events or continual process of development and becoming (as it is in Buddhism). In Western versions of interdependence, relation is retained, in the idea of a "web of life" or the "coupling" of distinct elements. However, process is lost: The sense of a Self - or anything that can be said to have an identity — is not understood as a perpetually evolving set of probabilities, constantly interacting with all other probabilities within the networks or environments that provide its context. To explain another way, consider catastrophe theory and complexity theory. Both assume a fairly radical continuity within self-organizing systems - a deep-seated interdependence-which necessitates that anything from a stock exchange to an organism must be understood in terms of general principles of connection, in terms of patterns of relation. However, both also tend toward mathemetization and the search for unifying laws, which must, in the end, default toward understanding those connections and relations as between discrete identities. Neither theory, 
in the end, can conceptualize identity as just those connections and relations inhering in each other: A universe not of things, but of hyper-complex and finally non-mathemetizable evolutions, intersecting vectors of probability that are so complex — and that evolve so quickly — that they cannot, in principle, ever be modeled fully and accurately. Olendzki's point, then, is that in authentic Buddhist traditions, "dependent origination" (a working synonym for interdependence) is "a very different idea than the interconnectedness of all things" [34] (p. 106). Bhutanese interdependence is not exactly "the web of life," or a network in which multiple nodes and hubs couple and intersect, or a series of general principles or mathematical forms or underlying laws. It is much more difficult to imagine. Buddhist interdependance is always on the move. It is anchored to nothing. It catches nothing.

A third Buddhist scholar, David McMahan, concedes that "contemporary Buddhism has reached out to embrace multiple late modern interdependencies, "given "countless findings in sociology, economics, quantum physics, and life sciences" [35] (p. 180), not to mention the tropes and manifestations of "the web, the network, the matrix, the nexus, the system" [35] (p. 181). But he also qualifies deeply, appealing to the distinct, and sometimes contradictory, histories of Buddhist philosophy: Western "interdependence" is not the interdependence of the traditional Pali Canon (the set of "original" Buddhist source texts). In fact, historically, interdependence has often been associated by Buddhists with "samsaric" life, the life of suffering and delusion. Burmese meditation master Mahasi Sayadaw once described interdependence as "dreadful" [35] (p. 182). McMahan does conclude that "the Mahayana" (one strain of Buddhism practiced in the Himalayas, distinct from the "original" Therevada) is "more amenable to idealist interpretations" [35] (p. 182) of interdependence, inherited, in the West, from German Romanticism; however, he cautions us not to forget the contested history of interdependence within Buddhism itself, a contestation that continues. The basic point is that "interdependence" is not a term that has ever been codified with precision, anywhere. Perhaps it is a term that, in principle, can never be codified with precision, that can only be articulated as a provisional, incomplete, local, and partially inaccurate concept. Feminist epistemologist, Lorraine Code vexes the issue further in her book, Ecological Thinking. She also aims to specifically reject substantialism, which she defines as "inquiry directed toward analyzing discrete, disparate beings, events, and items." But, as she is quick to note, proposing an alternate mode of inquiry based on cursory notions of interdependence is equally unwelcome: "ecological thinking is as available for feeding self-serving romantic fantasies as for inspiring socially responsible transformations" [36] (p. 6).

To briefly summarize this section so far, then: thinking through and activating new policies that engage "interdependence" and "coupling" can be naïve, perhaps self-defeating, for at least two reasons. One, because of our entrenched substantialist assumptions, we are currently ill-equipped to understand interdependence as the combination of interrelation and evolution (as various theories of chaos, catastrophe and complexity demonstrate). This is because to isolate an entity or principle-essentially, to define it - is to conceptually "take it out of time," in order that it retains its stand-alone status that can persist through time as an identity. Two, we often fail to recognize that the definition and conceptualization of interdependence itself has a complex and disputed history that is still unresolved, even in those cultures and histories that have thought about it for centuries. In fact, the more "interdependence" is scrutinized in its intellectual history, the more difficult the task of defining it becomes.

This issue of definition raises a third difficulty for Western notions of interdependence, a difficulty that is almost impossible to articulate without lapsing into what the Western mind would generally 
consider contradiction or insoluble paradox (partly because Aristotle bequeathed to us the Law of Non-Contradiction, which has rooted so deeply in the Western mind that it has become common sense). This third difficulty seems to overturn or loop back into the first two in a manner that threatens conceptual disintegration, because in some of the domains of Western thought where we are increasingly theorizing interdependence, we may have actually over-compensated for substantialism and lost an important nuance. Many of our process philosophies and theologies finally over critique the notion of reification or, as Loy names it, the "atomized individual." To put in technical language, we mistakenly identify substance exclusively with singularity, where "singularity" means absolute uniqueness or absolute difference from everything else that does, has or will exist. In doing so, we miss the possibility that events or occasions, too, can be singularities. The unfortunate result, theoretically, is an insistence on an interdependence that excludes or has no place for singularity, an interdependence where everything partakes of everything else and so, in a sense, is a part of everything else. But this is hardly the Bhutanese sense of interdependence, where one must hold in mind, simultaneously, two registers or dimensions of reality, often distinguished as "ultimate" and "relative". Ultimate reality is empty: "utter" and "sublime" contingency [37] (pp. 20,77), the evolutions and vectors of probability that mutually create each other in an infinitude of what Buddhists often call "dependant co-arising" or "dependant origination." Ultimate reality is the Truth, and true interdependence, but it cannot be explained or mathematized or captured by any other symbol system. It is pure insight, not the material of scholarship or inquiry. But one must still negotiate a world where self and other persist, where things have a provisional and perceived reality. One cannot communicate within a community, or navigate a social world, or even survive, if one simply perceives or comprehends reality accurately as a seething process-relational onflow. So human perceptions and conceptions must, on a daily basis, be necessary fictions, oversimplified and literally falsified. This is relative reality. In a mind-bending twist, relative reality, in turn, can be understood as how perceptions and conceptions function for human consciousness within ultimate reality. So the two registers are not finally distinct: the first is simply part of the second. Misrecognition of process and relation-whether witting or unwitting - is simply another example of process and relation in action.

Western interdependence is often monocular; Buddhist interdependence - at least in Himalayan traditions - is parallax: it holds ultimate and relative reality in mind at the same time, without considering such overlap an intellectual hazard or breakdown. Thus, Western "interdependent" policy could be paralyzed by unexpected consequences in ways that Bhutanese policy might not. It is, in one sense, true that things are theoretically subsumed into the web of life. But things will have their way: the world will continually appear to us as a substantialist set of discrete items, even when those items are seen to interact with each other within complex systems. Until one can seize both ontological truths at the same instant, the hope for truly interdependent policies is in question.

\section{Conclusion: How to Respond?}

Luckily, it is not true that all Western process thought falls into the fallacy noted above. The West's finest process thinker, the mathematician and physicist Alfred North Whitehead, pointed out this very problem in his masterpiece, Process and Reality, first published in the 1920s. In a critique of his influence and contemporary, Francis Bradley, Whitehead noted that too much relation with too little 
process results in a static oneness or "web" where everything becomes everything else [38] (p. 43). For Whitehead, the actualities of existence are brief events, not persistent things, but each of those events is absolutely unique: "the point to be emphasized," wrote Whitehead, "is insistent particularity" [38] (p. 43). Further, Whitehead concedes that for process-relational thinking to work, there must be two principles in operation at all times, which he names "Presentational Immediacy" and "Causal Efficacy." The first aligns roughly with relative reality, the latter with ultimate reality. His point is that we do experience phenomena in a crude way; it is a matter of pragmatics and survival. Yet, if our attention is open, we simultaneously experience ourselves within a propulsive, evolving world beyond and within us, where actuality is very different than the ways in which we perceive it.

It may be useful, then, to make a fourfold call if the West is to more effectively couple economic growth with a healthy environment. The first two propositions are abstract and heady, the last two more concrete and practical:

(1) We need to study, integrate and advocate further the strains of Western thought that emphasize "process-relational" philosophy consistent with—or at least not inconsistent with-Mahayana Buddhist conceptions of interdependence. It would be impossible to fully explain the core ideas and general history of process-relational philosophy here; that would quite literally take a book. But it is possible to recommend some thinkers who typify those strains of thought, as further reading. They would include especially two seminal thinkers of the twentieth century: Whitehead, mentioned above, and philosopher of religion Charles Hartshorne. They would also include an increasing number of current thinkers such as philosopher of science Isabelle Stengers, sociologist Bruno Latour, feminist theologian Catherine Keller, and social theorist Brian Massumi. (There are many other recent thinkers who take up process-relational ideas, most notably Gilles Deleuze; however, many of them are simply too arcane to recommend to readers who are not deeply conversant with the terminology of "continental theory" that is still active in the Humanities.)

(2) Further to the previous proposition, we need to distinguish between types of process thinker in the West, in order to separate out those useful thinkers who are able to gesture at the simultaneous apprehension of relative and ultimate reality described above, and those who are not. As philosopher Graham Harman has argued, thinkers such as Whitehead and Latour represent the strain of process philosophy that harmonizes interconnection with determinate singularity in an onrush of process, so that, in Whitehead's words, "the many become one and are increased by one" [38] (p. 21). On the other hand, Harman notes, thinkers like Henri Bergson, Gilles Deleuze, Manuel DeLanda, Ian Hamilton Grant and others often lumped with Whitehead do not constitute an "alliance" of process-relational thinkers. Rather, they represent a profound schism in their belief that singularities are "derivative," and that any talk of "discrete cinematic instants" - a fancy phrase for singularities —is "nonsense" [39] (p. 294). In other words, they tend to lapse back into the third problem, also described above. As such, they need not be studied and advocated. Indeed, they may muddle the problem and set back any practical advances in process-relational thought as it may relate to Himalayan Buddhist sensibilities and apply to actual policy. 
(3) To veer suddenly, it is also true that some policy actors in Bhutan might not agree with the philosophizing here. In fact, some seem quite willing to concede that GNH is portable, that other, non-Buddhist, states can and must learn from Bhutan's longstanding experiment with happiness. Most significantly, a UN General Assembly resolution in 2011 defined happiness as a "fundamental human goal" that encapsulates the Millennium Development Goals. Bhutan was a co-sponsor of the resolution and was designated to lead an international process of developing a happiness framework based on its GNH experience to be operationalized voluntarily by UN member states.

(4) To be highly practical, we might also urge that the ecological economics and complexity literature, including, especially, the "grey literature," needs to be taken more seriously, and granted greater exposure. This literature provides a range of suggested policy tools and approaches that recognize and respond to the interdependent and complex nature of economic and ecological systems. It demonstrates that such interdependent systems require not the linear cause and effect assumptions underlying much Western policymaking, but, instead, policy tools that benefit from an infusion of complexity and interdependence. More specifically, these policy instruments and processes would be flexible, integrated across a range of policy fields, open to mistakes, and capable of promoting continuous learning and encouraging self-organization [40-47]. This may include deliberative policy design tools that engage multiple stakeholder perspectives; regular policy review, including review of well-functioning policies; multiple interventions for the same issue; and integrated monitoring and assessment instruments. A useful example can be drawn from Bhutan. The Bhutanese policy design process centres around a GNH policy screening tool [11]. The tool engages a range of diverse stakeholders in a deliberative multidimensional process of discussion, reflection and learning. Stakeholders collectively evaluate a proposed policy against a set of 26 screening questions rooted in the multiple dimensions of GNH. A proposed mining policy, for example, would be collectively evaluated for its impact not only on economic growth and equity, but its potential impact on pollution, land degradation, conservation, people's participation in decision-making, corruption, gender equality, family life and spirituality, among other dimensions. A policy must achieve a certain ranking across the 26 questions in order to be further considered. The policy implementation process is then intended to monitor for unintended consequences that generate learning that can be mitigated or incorporated into the process. The tool is not without its challenges, but it represents a clear approach to locating interdependence at the centre of policy design.

There are more questions to be raised, which cannot be answered here. Two important ones: is GNH fully responsible for its reported successes? Or are other factors-its small population, its relationship with India, its non-colonial history-just as, or more, important in accounting for the reported success of GNH? And has Bhutan's recent transition to democracy and increasing engagement with the outside world introduced a waterfall of new variables that complicate GNH within Bhutan and its relevance for the West? At any rate, it may be time for the horizontal world of globalization to look up for answers, to the roof of the world, where vertical and horizontal, relative and ultimate, are not seen as absolute opposites. 


\section{Author Contributions}

The authors shared equally in the intellectual development and writing of the paper. Randy Schroeder developed the original idea and wrote the section on interdependence in the west. Kent Schroeder wrote the section on interdependent policy in Bhutan. Both authors contributed to writing the introduction and conclusion.

\section{Conflicts of Interest}

The authors declare no conflict of interest.

\section{References}

1. Bok, D. The Politics of Happiness; Princeton University Press: Princeton, NJ, USA, 2010.

2. Dessallien, R.L. Democracy, Good Governance and Happiness: Some Views from the Kingdom of Bhutan; Centre for Bhutan Studies: Thimphu, Bhutan, 2005; p. 40.

3. GNH Commission. Tenth Five Year Plan 2008-2013. Volume 1: Main Document; GNH Commission: Thimphu, Bhutan, 2009; p. 170.

4. RGoB. Bhutan National Human Development Report 2005; Royal Government of Bhutan: Thimphu, Bhutan, 2005; p. 18.

5. Thinley, J.Y. What is Gross National Happiness? In Rethinking Development, Proceedings of the Second International Conference on Gross National Happiness, Antigonish, NS, Canada, 20-24 June 2005; Centre for Bhutan Studies: Thimphu, Bhutan, 2005; pp. 3-11.

6. Ura, K. The Bhutanese Development Story; Centre for Bhutan Studies: Thimphu, Bhutan, 2003; p. 2.

7. Braun, A.A. Gross National Happiness in Bhutan: A Living Example of an Alternative Approach to Progress. Bachelor's Thesis, University of Pennsylvania, Philadelphia, PA, USA, 2009.

8. Ura, K.; Alkire, S.; Zangmo, T. Case Study: Bhutan. Gross National Happiness and the GNH Index. In World Happiness Report; Helliwell, J., Layard, R., Sachs, J., Eds.; Earth Institute, Columbia University: New York, NY, USA, 2012; pp.108-158.

9. McDonald, R. Towards a new conceptualization of Gross National Happiness and its foundations. J. Bhutan Stud. 2005, 12, 23-46.

10. Rinzin, C. On the Middle Path: The Social Basis for Sustainable Development in Bhutan; Copernicus Institute for Sustainable Development and Innovation: Utrecht, Netherlands, 2006.

11. GNH Tools: GNH Policy \& Project Screening Tools. Available online: http://www. grossnationalhappiness.com/gnh-policy-and-project-screening-tools/ (accessed on 26 February 2014).

12. Hewavitharana, B. Framework for operationalizing the Buddhist concept of Gross National Happiness. In Gross National Happiness and Development, Proceedings of the First International Seminar on Operationalizing Gross National Happiness, Thimphu, Bhutan, 18-20 February 2004; Ura, K., Galay, K., Eds.; Centre for Bhutan Studies: Thimphu, Bhutan, 2004.

13. Lokamitra, D. The centrality of Buddhism and education in developing Gross National Happiness. In Gross National Happiness and Development, Proceedings of the First International Seminar on Operationalizing Gross National Happiness, Thimphu, Bhutan, 18-20 February 2004; Ura, K., Galay, K., Eds.; Centre for Bhutan Studies: Thimphu, Bhutan, 2004. 
14. Mathou, T. The politics of Bhutan: Change in continuity. J. Bhutan Stud. 2000, 2, 250-262.

15. Priesner, S. Gross National Happiness: Bhutan's vision of its development and its challenges. In Indigeneity and Universality in Social Science; Mukherji, P.N., Sengupta, C., Eds.; Sage: London, UK, 2004; pp. 212-230.

16. Tashi, K.P. The role of Buddhism in achieving Gross National Happiness. In Gross National Happiness and Development, Proceedings of the First International Seminar on Operationalizing Gross National Happiness, Thimphu, Bhutan, 18-20 February 2004; Ura, K., Galay, K., Eds.; Centre for Bhutan Studies: Thimphu, Bhutan, 2004.

17. Ekman, P.; Davidson, R.; Ricard, M.; Wallace, B.A. Buddhist and psychological perspectives on emotions and wellbeing. Curr. Dir. Psychol. Sci. 2005, 14, 59-63.

18. Ricard, M. The Dalai Lama: Happiness from within. Int. J. Wellbeing 2011, 1, 274-290.

19. Rose, L. The Politics of Bhutan; Cornell University Press: Ithaca, NY, USA, 1977.

20. GNH Commission; United Nations Development Program. Bhutan National Human Development Report 2011; GNH Commission: Thimphu, Bhutan, 2011.

21. National Statistics Bureau. Statistical Yearbook of Bhutan 2011; National Statistics Bureau, Royal Government of Bhutan: Thimphu, Bhutan, 2011.

22. Wildlife Conservation Division. Analysis of the Contributions of Protected Areas to the Social and Economic Development of Bhutan at National Level; Ministry of Agriculture and Forests: Thimphu, Bhutan, 2010.

23. Myers, N. Threatened biotas: "hot-spots" in tropical forests. Environmentalist 1988, 8, 187-208.

24. Ministry of Agriculture. Biodiversity Action Plan; Royal Government of Bhutan: Thimphu, Bhutan, 2009.

25. Transparency International: Corruption Perceptions Index 2012. Available online: http://cpi.transparency.org/cpi2012/results/ (accessed on 16 October 2013).

26. Schroeder, K. The Politics of Gross National Happiness: Image and Practice in the Implementation of Bhutan's Multidimensional Development Strategy. Ph.D. Thesis, University of Guelph, Guelph, ON, Canada, 2014.

27. Nyaupane, G.; Timothy, D. Power, regionalism and tourism policy in Bhutan. Ann. Tourism Res. 2010, 37, 969-988.

28. Schroeder, K.; Sproule-Jones, M. Culture and policies for sustainable tourism: A South Asian comparison. J. Comp. Pol. Analysis Res. Pract. 2012, 14, 330-351.

29. National Statistics Bureau. Bhutan Poverty Analysis 2012; Royal Government of Bhutan and World Bank: Thimphu, Bhutan, 2013.

30. GNH Commission. Eleventh Round Table Meeting. Turning Vision Into Reality: The Challenges Confronting Bhutan; Gross National Happiness Commission: Thimphu, Bhutan, 2011.

31. National Commission for Women \& Children. Natl. Plan Action Gend. 2008-2013; Royal Government of Bhutan: Thimphu, Bhutan, 2008.

32. McDonald, R. The future of Gross National Happiness. In Gross National Happiness: Practice and Measurement, Proceedings of the Fourth International Conference on Gross National Happiness, Thimphu, Bhutan, 24-26 November 2008; Ura, K., Penjore, D., Eds.; Centre for Bhutan Studies: Thimphu, Bhutan, 2009. 
33. Loy, D.R. Money, Sex, War, Karma: Notes for a Buddhist Revolution; Wisdom Publications: Boston, MA, USA, 2008.

34. Olendzki, A. Unlimiting Mind: The Radically Experiential Psychology of Buddhism; Wisdom Publications: Boston, MA, USA, 2010.

35. McMahan, D.L. The Making of Buddhist Modernism; Oxford University Press: Oxford, UK, 2008.

36. Code, L. Ecological Thinking: The Politics of Epistemic Location; Oxford University Press: Oxford, UK, 2006.

37. Batchelor, S. Verses from the Center: A Buddhist Vision of the Sublime; Riverhead: New York, NY, USA, 2000.

38. Whitehead, A.N. Process and Reality, corrected ed.; Griffin, D.R., Sherburne, D.W., Eds.; Free Press: New York, NY, USA, 1978.

39. Harman, G. Response to Shaviro. In The Speculative Turn: Continental Materialism and Realism; Bryant, L., Srnicec, N., Harman, G., Eds.; Re.press: Melbourne, Australia, 2011; pp. 291-303.

40. Bankes, S.C. Tools and techniques for developing policies for complex and uncertain systems. Proc. Natl. Acad. Sci. USA 2002, 99, 7263-7266.

41. Duit, A.; Galaz, V.; Eckerberg, K.; Ebbeson, J. Governance, complexity and resilience. Global Environ. Change 2010, 20, 363-368.

42. Folke, C.; Hahn, T.; Olsson, P.; Norberg, J. Adaptive governance of social-ecological systems. Ann. Rev. Environ. Resour. 2005, 30, 441-473.

43. Morçöl, G. A Complexity Theory for Public Policy; Routledge: New York, NY, USA, 2012.

44. Organization for Economic Co-operation and Development. Applications of complexity science for public policy: New tools for finding unanticipated consequences and unexpected opportunities. In Proceedings of Report on the OECD Global Science Forum Workshop, Erice, Sicily, Italy, 5-7 October 2008; OECD: Paris, France, 2009.

45. Pahl-Wostl, C. A conceptual framework for analyzing adaptive capacity and multi-level learning processes in resource governance regimes. Global Environ. Change 2009, 19, 354-365.

46. Swanson, D.; Venema, H.; Barg, S.; Tyler, S.; Drexhage, J.; Bhadwal, S.; Tomar, S.; Nair, S.; Kelkar, U. Adaptive policies: Meeting the policymakers challenge in today's complex, dynamic and uncertain world. In Proceedings of the CAIWA International Conference on Adaptive and Integrated Water Management: Coping with Complexity and Uncertainty, Basel, Switzerland, 12-15 November 2007. Available online: http://www.newater.uni-osnabrueck.de/caiwa/data/ papers\%20session/G2/Adaptive\%20Policies\%20-\%20CAIWA\%20Paper.pdf (accessed on 24 March 2014).

47. Walker, W.; Marchau. V. Dealing with uncertainty in policy analysis and policy-making. Integrated Assess. 2003, 4, 1-4.

(C) 2014 by the authors; licensee MDPI, Basel, Switzerland. This article is an open access article distributed under the terms and conditions of the Creative Commons Attribution license (http://creativecommons.org/licenses/by/3.0/). 